\section{Treatment of the Buried Bumper Syndrome using a Savary Dilator}

The buried bumper syndrome is a rare but serious complication of percutaneous endoscopic gastrostomy (PEG). Although a variety of nonoperative techniques have been used to manage the syndrome $[1,2,3]$, surgical intervention is necessary to rectify the problem in most cases [4]. We report on an endoscopic method for treating the buried bumper syndrome, using a Savary dilator over a guide wire. Between January 2001 and May 2005, 12 patients were admitted to our gastroenterology unit with buried bumper syndrome. The PEG tube was cut $2-3 \mathrm{~cm}$ above skin level. Under endoscopic visualization, a guide wire was inserted through the gastrostomy tube into the stomach. The guide wire was grasped with a snare and withdrawn through the mouth. The endoscope was reinserted into the stomach. In seven patients, in whom the bumper was overgrown by gastric mucosa, endoscopic incision using a needle-knife was necessary ( $\bullet$ Figure 1). A 21-Fr Savary dilator was then passed over the guide wire to displace the bumper, together with the remnant of the tube, into the stomach ( $\bullet$ Figure 2 ). The bumper was snared and removed endoscopically.

It was possible to remove the buried bumpers in this way from all 12 patients. In 11 patients the procedure was tolerated without any incident; in one patient the needle-knife procedure led to a bleeding episode which was treated endoscopically. A new PEG was placed in all 12 patients within 5 days.

The endoscopic removal of an embedded bumper using a Savary dilator was first reported by Klein et al. [4]. Ma et al. [5] exposed completely buried bumpers by needle-knife incision and removed them with a foreign-body forceps. We used a combination of these approaches. To our knowledge, this is the largest reported series of patients with buried bumper

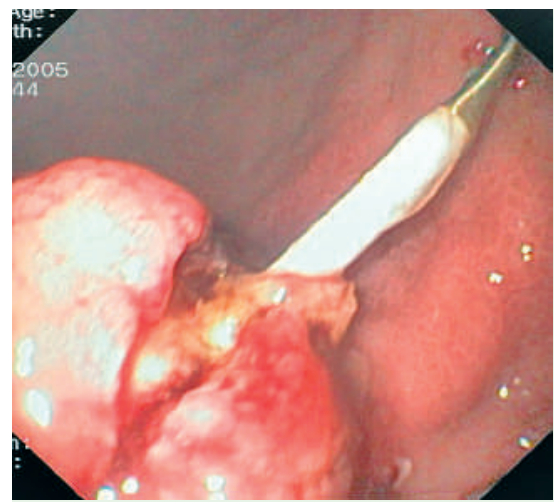

Figure 1 Endoscopic incision of the gastric mucosa using a needle-knife in a patient whose internal percutaneous endoscopic gastrostomy (PEG) bumper was completely overgrown.

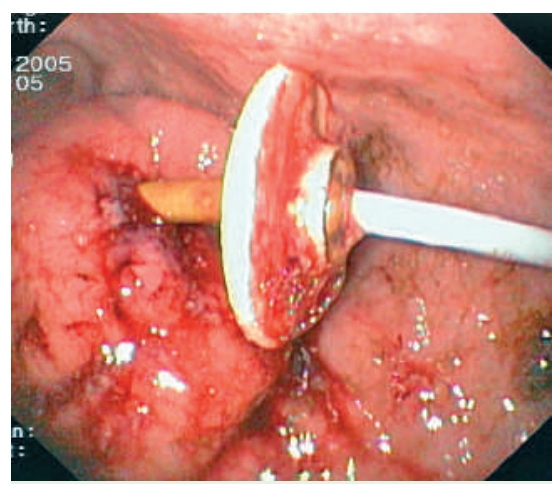

Figure 2 The internal bumper is displaced into the stomach by passing a Savary dilator over a guide wire.

syndrome treated successfully using one defined endoscopic method.

The endoscopic method we have described here, using a Savary dilator over a guide wire, allows safe removal of embedded PEG bumpers and might replace surgery in the treatment of the buried bumper syndrome.

Endoscopy_UCTN_Code_CCL_1AZ_2AZ

\section{B. Rieder, A. Pfeiffer}

Medical Department, Klinikum Memmingen II, Memmingen Academic Teaching Hospital of the LudwigMaximilians University, Munich, Germany

\section{References}

1 Venu RP, Brown RD, Pastika BJ, Erikson LW. The buried bumper syndrome: a simple management approach in two patients. Gastrointest Endosc 2002; 56: 582-584

2 Sauer B, Staritz M. Buried bumper: a new method of non-surgical removal. Z Gastroenterol 2004; 42: 227-232

3 Strock P, Weber J. Buried bumper syndrome: endoscopic management using a balloon dilator. Endoscopy 2005; 37: 279

4 Klein S, Heare BR, Soloway RD. The "buried bumper syndrome": a complication of percutaneous endoscopic gastrostomy. Am J Gastroenterol 1990; 85: 448 - 450

$5 \mathrm{Ma} M M$, Semlacher EA, Fedorak RN et al. The buried gastrostomy bumper syndrome: prevention and endoscopic approaches to removal. Gastrointest Endosc 1995; 41: 505-508

\section{Bibliography}

DOI $10.1055 / \mathrm{s}-2006-925183$

Endoscopy 2007; 39: E115

(c) Georg Thieme Verlag KG Stuttgart · New York . ISSN 0013-726X

\section{Corresponding author}

\section{B. Rieder, MD}

Klinikum Memmingen, Medizinische Klinik II Bismarckstr. 23, 87700 Memmingen Germany

Fax: +49-8331-70-2395

Rieder-MM@arcor.de 